\title{
Ultrasonically Aided Cross-flow Membrane Filtration for Latex Wastewater
}

\author{
Abdul Latif Ahmad, Nuur Fahanis Che Lah* and Suzylawati Ismail \\ School of Chemical Engineering, Engineering Campus, Universiti Sains Malaysia, \\ 14300 Nibong Tebal, Pulau Pinang, Malaysia \\ *Corresponding author: fahanischelah87@gmail.com
}

Published online: 25 February 2018

To cite this article: Ahmad, A. L., Che Lah, N. F. \& Ismail, S. (2018). Ultrasonically aided cross-flow membrane filtration for latex wastewater. J. Phys. Sci., 29(Supp. 1), 57-65, https://doi.org/10.21315/jps2018.29.s1.8

To link to this article: https://doi.org/10.21315/jps2018.29.s1.8

\begin{abstract}
An ultrasonically-aided membrane filtration system that offers clean membrane after being fouled by latex wastewater was developed. Characterisation of latex wastewater was investigated to determine the best and suitable membrane used in this filtration system. The effect of frequency of the ultrasound waves and the sonication time were investigated. All parameters were compared based on the calculation of coefficient $k$ value and the decay ratio (DR\%). In overall, low frequency (35 $\mathrm{kHz}$ ) gives better cleaning efficiency than high frequency $(130 \mathrm{kHz})$ with DR\% differences value of $12.2 \%$. The permeate water quality was measured by the permeate turbidity. Even though the quality of permeate flux after the filtration by cleaned-membrane was lower than the filtration by uncleaned-membrane, the differences of these two were acceptable with $1 \%$ differences of rejection rate.
\end{abstract}

Keywords: Ultrasonic, frequency, anti-fouling, latex wastewater, membrane filtration

\section{INTRODUCTION}

Wastewater from concentrated latex skim crepe industry contains sulfate which comes from sulfuric acid in the skimming process with its concentration ranges between 644 and $1688 \mathrm{mg}^{-1}$ and has the pollutants expressed in term of the 5-day biological oxygen demand $\left(\mathrm{BOD}_{5}\right)$ at the value of about $7000-15000 \mathrm{mg}^{-1}$. The conventional treatment plant of this industry usually comprises the series of big anaerobic ponds followed by oxidation ponds. Instead of the anaerobic ponds, the aeration ponds were used to solve the bad odour problems but this method cannot overcome the $\mathrm{BOD}_{5}$ of the treated wastewater and large area problems. ${ }^{1}$ 
Yuan Gao et al. improved the system by using a frequency of $20 \mathrm{kHz}$ and a power of $16 \mathrm{~W}$ applied to a cross-flow ultrafiltration system to investigate the ultrasonic control of surface-water fouled ceramic membranes. ${ }^{2}$ It is proven that ultrasound was effective in improving the normalised permeate flux of a surface water, from 0.21 in the absence of ultrasound to 0.70 with the aid of ultrasound. Alternatively, membrane filtration could become a method for isolating value-added product from latex wastewater and discharging minimal amount of effluent, thus making latex processing an environmental friendly process. This process could achieve "zero discharge" as all the products from the concentration process have commercial value. $^{3}$ The retentate can be used as part of latex product's raw material while the permeate water can be used for rinse purposes. To prevent fouling, membrane requires a surface chemistry which prefers binding to water over other materials. This implies that the material must be very hydrophilic. The occurrence of fouling is very difficult and complicated to describe theoretically. Flux may also be described by a resistances-in-series model, in which a resistance of a cake layer is in series with the membrane resistance. ${ }^{4}$

To minimise the fouling problem that occurs in the membrane filtration system, several techniques can be applied. These techniques can be divided into two sections: controlling methods and cleaning methods. In controlling method, there are several techniques that have been used by researchers such as feed pretreatment, membrane material selection and membrane surface modification..$^{5-8}$ For cleaning methods, it includes chemical, mechanical and hydrodynamic (turbulent promoters, backflushing, pulsing, shocking, pulsatile flow, gas sparging, electrical and ultrasonic cleaning) cleaning. ${ }^{9-18}$ An ultrasonic-assisted membrane filtration process has been developed recently. ${ }^{19-22}$ This technology has been extensively used as a method of cleaning materials because of the cavitation phenomenon. ${ }^{23}$ It was reported that the permeability enhancement resulted from the acoustic pressure, agitation and micro-current of feed fluid by ultrasound irradiation. Chai et al. found that the increase in permeate flux could be ascribed to the increase in bulk mass transfer in the concentration polarisation layer near the membrane. ${ }^{18}$ Several factors should be considered when using ultrasound irradiation as a membrane cleaning method. This study will focus on the effect of frequency of the ultrasound waves, water bath temperature and the sonication time.

\section{EXPERIMENTAL}

Cellulose acetate membrane from Sterlitech Corporation was used in this study. These flat sheet membranes were placed in between acrylic membrane holder (Sterlitech Co. USA) with an effective membrane area of $3,315 \mathrm{~mm}^{2}$. According to manufacturers' specification, each cellulose acetate membrane filter has excellent 
dimensional stability after autoclaving or steam sterilising and is completely unaffected by temperatures up to $135^{\circ} \mathrm{C}\left(275^{\circ} \mathrm{F}\right)$. The exclusive impregnation process used in production results in a cellulose acetate membrane filter with burst strength of 8.9631 bars, uniform pore size and consistent flow rates for reliable performance. The latex solution Perbunan-N-Latex 3415 (PolymerLatex GmbH, Germany) was used as it has similar characteristic as the real latex wastewater tested.

For this study, the membrane unit was completely immersed in an ultrasonic bath (Elmasonic TI-H-5, Germany) of 3.51 capacity and a piezo electric transducer attached at nominal power of $400 \mathrm{~W}$ output for an emission of 35 and $130 \mathrm{kHz}$ ultrasound. The feed was circulated in the cross flow ultrafiltration unit by a peristaltic pump (FLEX-PRO ${ }^{\circledR}, A 4 V$ Series) operated with pressure not exceeding 6.5 bar. During the experimental runs, the retentates were recycled back to the feed tank. All experiments were conducted using $500 \mathrm{ml}$ of skim latex as the feed volume and re-circulated in the ultrafiltration (UF) system at a feed flow rate of $500 \mathrm{ml} \mathrm{h}^{-1}$. The trans-membrane pressure (TMP) was set at 2 bar as recommended by previous study. ${ }^{3}$ Every experiment consists of 4 cycles and every cycle needs $30 \mathrm{~min}$ of an ultrafiltration membrane process. The permeate weights were recorded online at every $30 \mathrm{~s}$ interval by computerised system.

Study on the effect of frequency and sonication time was carried out at $35 \mathrm{kHz}$ and $130 \mathrm{kHz}$ of ultrasonic frequency with 2,5 and 10 min of sonication time respectively. The sonication will be supplied all the time or in intermittent way. The trans-membrane pressure (TMP) is defined as a pressure gradient of the membrane. It was fixed at 3 bars for the compaction process with the deionised water and at 2 bars along the separation process. The velocity of the feed solution was maintained at $500 \mathrm{ml} \mathrm{h}^{-1}$.

\section{RESULTS AND DISCUSSION}

\subsection{Effect of Ultrasonic (US) to Ultrafiltration (UF)}

The effect of US at 35 and $130 \mathrm{kHz}$ frequencies on the UF process were studied. Figure 1 shows the performances of permeate flux of UF for latex wastewater solution over time with different US frequencies cleaning procedure. The result indicated that the flux ratio after cleaning was significantly enhanced by the US at both frequencies. This result also showed that the trends of the flux performance for US enhanced experiments were similar with the trends of the flux performance without US, indicating that US did not alter the basic of UF processes. This finding was similar to the result from Cai et al. ${ }^{19}$ They found that the flux of 
dextran solution after the US treatment with 28,45 and $100 \mathrm{kHz}$ frequency had a similar trend with the performance without US treatment.

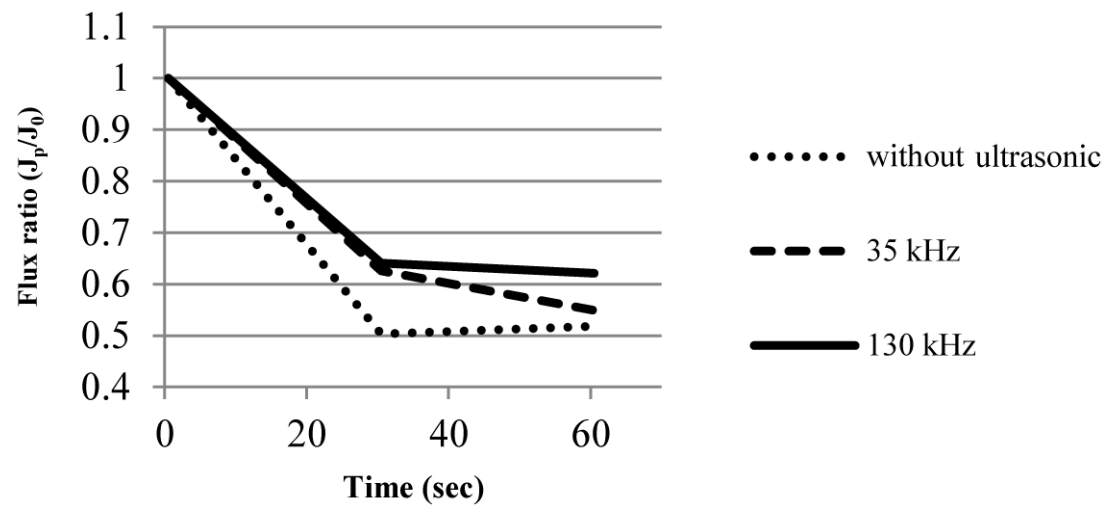

Figure 1: Ultra-filtration process with or without ultrasound irradiation at trans-membrane pressure of 2 bars.

\subsection{Effect of Frequency}

The first series of ultrasonic cleaning experiments examined the relationship between the cleaned flux ratios on frequencies. At frequency larger than $18 \mathrm{kHz}$, high intensity sound fields produced a dynamic agitation and shear stresses, which affect the properties, particularly viscosity. ${ }^{23}$ To investigate the effect of frequency, runs were performed with the fouled membrane surface facing away from the transducer with different sonication time. Altering ultrasound input to medium frequency changed both of the wave interactions with the fluid and the characteristics of the cavitation bubbles formed. For example, at higher frequency, sound was attenuated more readily. Therefore, acoustic energy may not be available for cleaning throughout the system. In addition, the maximum size bubbles attained was smaller than with lower frequencies. However, although the bubbles tend to collapse less violently, the number of bubble collapse per time was larger which create lower temperatures and pressures.

As can be seen from Table 1 , at $25^{\circ} \mathrm{C}$ and 5 min sonication time of operating condition, the lower DR\% value was at frequency $35 \mathrm{kHz}$ with $64.69 \%$ rather than $76.87 \%$ at frequency $130 \mathrm{kHz}$. This finding was similar to several reports by other researchers. Each researcher found out that a better permeate flux could be achieved after cleaning procedure with lower frequency. Lower DR value indicated a better antifouling property of the membrane after cleaning. At low frequency, the formation of cavity bubbles grew during the rarefaction cycle of ultrasound wave. An acoustic streaming effects generated by the destruction of a large numbers 
of cavity bubbles enhanced the flux permeation. While at high frequency, less cavitation in solution was produced. Thus, less number of bubbles and their low collapse lead to less turbulence in fluid medium that will lower the detachment and movement of foulant particles from the membrane pores.

$$
J_{P} / J_{P 0}=\operatorname{a} \cdot \exp \left\{-k\left[t-(n-1) T_{c}\right\}\right.
$$

Table 1: The DR\% of cellulose acetate membrane with ultrasonic cleaning method at $25^{\circ} \mathrm{C}$ with $5 \mathrm{~min}$ of sonication time.

\begin{tabular}{cccccc}
\hline \multirow{2}{*}{ Frequency $(\mathrm{kHz})$} & \multirow{2}{*}{ Temperature $\left({ }^{\circ} \mathrm{C}\right)$} & \multicolumn{4}{c}{ DR $(\%)$} \\
\cline { 3 - 6 } & & Cycle 1 & Cycle 2 & Cycle 3 & Average \\
\hline 35 & 25 & 64.840183 & 64.38356 & 64.84018 & 64.68797 \\
130 & 25 & 78.787879 & 77.27273 & 74.54545 & 76.86868 \\
\hline
\end{tabular}

Table 2: The coefficient $\mathrm{k}$ value with ultrasonic cleaning method at $25^{\circ} \mathrm{C}$.

\begin{tabular}{cccccc}
\hline \multirow{2}{*}{ Frequency $(\mathrm{kHz})$} & Time $(\mathrm{min})$ & \multicolumn{5}{c}{$k\left(1 \times 10^{-4}\right)$} \\
\cline { 3 - 6 } & & Cycle 1 & Cycle 2 & Cycle 3 & Average \\
\hline \multirow{3}{*}{35} & 5 & 1.68 & 1.06 & 8.01 & 1.17888 \\
& 10 & 3.07 & 1.41 & 1.36 & 1.94783 \\
& 2 & 5.15 & 3.81 & 1.32 & 3.03322 \\
\hline \multirow{2}{*}{130} & 5 & 3.56 & 2.02 & 7.48 & 2.1074 \\
& 10 & 2.07 & 1.98 & 1.16 & 1.7351 \\
\hline
\end{tabular}

In order to show more clearly the frequency effect of ultrasound waves as a cleaning method, the coefficient $k$ was calculated from Equation 1. At high $k$ value, the permeability of the membrane decreased faster. Figure 2 shows that $k_{35}<k_{130}$ which indicated that the cleaning by using $35 \mathrm{kHz}$ ultrasonic frequency was good in increasing the permeability of the membrane after fouled by the latex particles compared to cleaning with $130 \mathrm{kHz}$. This could be explained by the following equation that correlates the US attenuation with its frequency:

$$
A=\alpha f L
$$

where $A$ is the attenuation (dB), $\alpha$ is the attenuation coefficient $\left(\mathrm{dB} \mathrm{kHz}^{-1} \mathrm{~m}^{-1}\right)$, $f$ is the frequency $(\mathrm{kHz})$ and $L$ is the path length (m). According to Equation 2, attenuation increased with the increasing US frequency when the US propagated in the same media through the same distance. Furthermore, in our system the US propagated first in water and then travelled through the outer case of the membrane 
holder which was made of acrylic, thus the attenuations were serious. Attenuation is a gradual loss in intensity of flux through a medium. As a result, the ultrasonic power that reached the UF membrane inside the membrane holder was low and decreased proportionally with the increase of US frequency. ${ }^{19,24}$

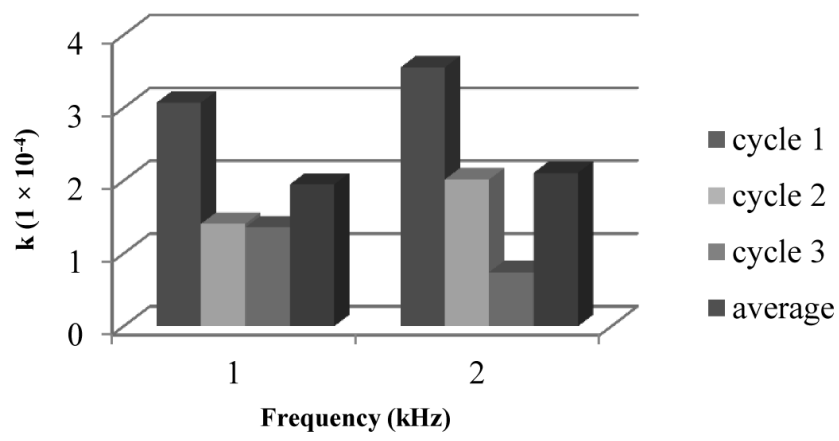

Figure 2: Effect of frequency on the coefficient $\mathrm{k}$ after every cleaning cycle.

Kobayashi et al. obtained similar results when studying cross-flow filtration of dextran irradiating membranes using 28,45 and $100 \mathrm{kHz}$ at a power intensity of $2.7 \mathrm{~W} \mathrm{~cm}^{-2}$ (the output power of the sonicator per unit area of the transducer surface) ${ }^{25}$ Additionally Kobayashi et al. observed nearly no effect on the flux in milk microfiltration with cellulose membrane and only a slight effect in peptone ultrafiltration with polysulphone membrane, when using a frequency of $100 \mathrm{kHz}$ although the power intensity was $23 \mathrm{~W} \mathrm{~cm}^{-2}$ (measured calorimetrically). ${ }^{24} \mathrm{On}$ the other hand, Lamminen et al. obtained different result as they used different type of membrane in their filtration system. ${ }^{26}$

Similarly, to sound waves, ultrasounds are spread by a series of compression and rarefaction (decompression) waves stimulated in the molecules of the medium through which it passes. The rarefaction cycle may exceed the repulsive forces of the liquid molecules, and cavitation bubbles (empty, gas and/or vapour-filled bubbles) will form with an adequately high power. Cavitation bubbles are formed when the pressure amplitude exceeds the tensile strength of liquid during the rarefaction of sound waves. This cavity may dissipate back into the liquid, grow to a resonant size and fluctuate or grow to a size at which the surface tension forces of the liquid cause it to collapse on itself. ${ }^{26}$ In aqueous system, the collapse of the cavitation bubble has important mechanical and chemical effects. Each cavitation bubble acts as a contained "hot spot" that engendered temperatures of about 4000$6000 \mathrm{~K}$ and pressures of 100-200 MPa at the bubble core. These processes result in fluid movement and may be able to remove parts of the foulant layer from the membrane surface and/or avoid the deposition of particles that lead to membrane fouling. ${ }^{27}$ 


\section{CONCLUSION}

On-line ultrasonic of the cellulose acetate ultrafiltration membrane system used in this investigation resulted in a significant increase in the permeate flux. On average, the permeate flux increased by approximately $24.21 \%$ under $35 \mathrm{kHz}$ of ultrasound frequency and approximately $27.24 \%$ under $130 \mathrm{kHz}$ of ultrasound frequency compared to the process without sonication. The ultrasonic assisted membrane can be utilised as one of the cleaning methods. The effect of frequency and water bath temperature has been thoroughly investigated. It was found that, a change in frequency caused significant impact to the membrane permeability. Low frequency gave higher impact to the membrane permeability after cleaning. As the water bath temperature increased, the cleaning efficiency increased.

\section{ACKNOWLEDGEMENTS}

The authors acknowledge the financial support provided by the Ministry of Higher Education (MOHE) Malaysia for Fundamental Research Grant Scheme (FRGS) (Grant no: 203/PJKIMIA/6071203) and Long-term Research Grant Scheme (LRGS) (Grant no: 203/PJKIMIA/6727101).

\section{REFERENCES}

1. Thonglimp, V., Srisuwan, G. \& Jkaew, P. (2005). Treatment of industrial latex wastewater by activated sludge system. Paper presented at the PSUUNS International Conference on Engineering and Environment, Serbia and Montenegro, Novi Sad, 19-21 May.

2. Gao, Y. et al. (2012). Ultrasonic control of UF membrane fouling by natural waters: Effects of calcium, $\mathrm{pH}$, and fractionated natural organic matter. J. Membr. Sci., 401-402, 232-240, https://doi.org/10.1016/j. memsci.2012.02.009.

3. Veerasamy, D. et al. (2009). Evaluating the use of in-situ ultrasonication to reduce fouling during natural rubber skim latex (waste latex) recovery by ultrafiltration. Desalin., 236(1-3), 202-207, https://doi.org/10.1016/j. desal.2007.10.068.

4. Mulder, M. (1997). Basic principal of membrane technology. Amsterdam: Kluwer.

5. Williams, C. \& Wakeman, R. (2000). Membrane fouling and alternative techniques for its alleviation. Membr. Technol., 124, 4-10, https://doi.org/ 10.1016/S0958-2118(00)80017-8. 
6. Goosen, et al. (2004). Fouling of reverse osmosis and ultrafiltration membranes: A critical review. Basingstoke: Taylor \& Francis.

7. Flemming, H. C. \& Schaule, G. (1988). Biofouling on membranes - A microbiological approach. Desalin., 70(1-3), 95-119, https://doi.org/ 10.1016/0011-9164(88)85047-1.

8. Jenkins, M. \& Tanner, M. B. (1998). Operational experience with a new fouling resistant reverse osmosis membrane. Desalin., 119(1-3), 243-249, https://doi.org/10.1016/S0011-9164(98)00165-9.

9. Lim, A. L. \& Bai, R. (2003). Membrane fouling and cleaning in microfiltration of activated sludge wastewater. J. Membr. Sci., 216(1-2), 279-290, https://doi.org/10.1016/S0376-7388(03)00083-8.

10. Xu, N. et al. (2003). Study on ceramic membrane bioreactor with turbulence promoter. Sep. Purif. Technol., 32(1-3), 403-410, https://doi.org/10.1016/ S1383-5866(03)00073-X.

11. Auddy, K. et al. (2004). Flux enhancement in nanofiltration of dye solution using turbulent promoters. Sep. Purif. Technol., 40(1), 31-39, https://doi. org/10.1016/j.seppur.2004.01.001.

12. Sondhi, R. et al. (2000). Crossflow filtration of chromium hydroxide suspension by ceramic membranes: Fouling and its minimization by backpulsing. J. Membr. Sci., 174(1), 111-122, https://doi.org/10.1016/ S0376-7388(00)00384-7.

13. Gupta, B. B. et al. (1993). Scaling up pulsatile filtration flow methods to a pilot apparatus equipped with mineral membranes. J. Membr. Sci., 80(1), 13-20, https://doi.org/10.1016/0376-7388(93)85128-J.

14. Howell, J. A. et al. (1993). Yeast cell microfiltration: Flux enhancement in baffled and pulsatile flow systems. J. Membr. Sci., 80(1), 59-71, https://doi. org/10.1016/0376-7388(93)85132-G.

15. Youravong, W. et al. (2010). Influence of gas sparging on clarification of pineapple wine by microfiltration. J. Food Eng., 96(3), 427-432, https://doi. org/10.1016/j.jfoodeng.2009.08.021.

16. Ahmad, A. L. \& Ibrahim, N. (2002). Automated electrophoretic membrane cleaning for dead-end microfiltration and ultrafiltration. Sep. Purif. Technol., 29(2), 105-112, https://doi.org/10.1016/S1383-5866(02)00066-7.

17. Pabby, S. S. H. R. A. et al. (2009). Handbook of membrane separations: Chemical, pharmaceutical, food and biotechnological application. Boca Raton: CRC Press.

18. Chai, X. et al. (1998). Ultrasound effect on cross-flow filtration of polyacrylonitrile ultrafiltration membranes. J. Membr. Sci., 148(1), 129135, https://doi.org/10.1016/S0376-7388(98)00145-8. 
19. Cai, M. S. et al. (2010). Mechanisms for the enhancement of ultrafiltration and membrane cleaning by different ultrasonic frequencies. Desalin., 263(13), 133-138, https://doi.org/10.1016/j.desal.2010.06.049.

20. Popovic, S. et al. (2010). Application of an ultrasound field in chemical cleaning of ceramic tubular membrane fouled with whey proteins. J. Food Eng., 101(3), 296-302, https://doi.org/10.1016/j.jfoodeng.2010.07.012.

21. Ahmad, A. L. et al. (2012). Membrane antifouling methods and alternatives: Ultrasound approach. Sep. Purif. Rev., 41(4), 318-346, https://doi.org/10.10 80/15422119.2011.617804.

22. Mirzaie, A. \& Mohammadi, T. (2012). Effect of ultrasonic waves on flux enhancement in microfiltration of milk. J. Food Eng., 108(1), 77-86, https://doi.org/10.1016/j.jfoodeng.2011.07.026.

23. Masselin, I. et al. (2001). Effect of sonication on polymeric membranes. J. Membr. Sci., 181(2), 213-220, https://doi.org/10.1016/S03767388(00)00534-2.

24. Kobayashi, T. et al. (2003). Ultrasound-enhanced membrane-cleaning processes applied water treatments: Influence of sonic frequency on filtration treatments. Ultrason., 41(3), 185-190, https://doi.org/10.1016/S0041624X(02)00462-6.

25. Kobayashi, T. et al. (1999). Ultrasound enhanced cross-flow membrane filtration. Sep. Purif. Technol., 17(1), 31-40, https://doi.org/10.1016/S13835866(99)00023-4.

26. Lamminen, M. O. et al. (2004). Mechanisms and factors influencing the ultrasonic cleaning of particle-fouled ceramic membranes. J. Membr. Sci., 237(1-2), 213-223, https://doi.org/10.1016/j.memsci.2004.02.031.

27. Radziuk, D. V. \& Möhwald, H. (2016). Ultrasonic mastering of filter flow and antifouling of renewable resources. ChemPhysChem., 17(7), 931-953, https://doi.org/10.1002/cphc.201500960. 